\title{
Use and effect of paediatric advanced life support skills for paediatric arrest in the A\&E department
}

\author{
T B Hassan
}

\begin{abstract}
Objectives-To define the use of paediatric advanced life support by the Leicestershire Ambulance and Paramedic Service (LAPS) and the A\&E department of a large university teaching hospital; and to identify the outcome and determine the factors that are consistent with a successful outcome.

Subjects and methods-The prehospital, accident and emergency (A\&E), and inpatient notes of all patients aged 0-16 years who had been admitted to the resuscitation room at the Leicester Royal Infirmary in cardiac arrest between 1 January 1992 and 31 December 1995 were reviewed. Cardiac arrest was defined according to the Utstein template for reporting of prehospital data.

Results-During the four year period, 51 cases of paediatric cardiac arrest were identified, with a median age of 3.2 years (range two days to 15 years). In eight patients, resuscitation was not attempted. Of the remaining $43,15(37 \%)$ were discharged from $A \& E$ to the intensive care unit. Five $(11.5 \%)$ ultimately survived to discharge from hospital. Subsequent neurological development was recorded as normal in four of the five. Of the patients who had a prehospital cardiac arrest and were initially resuscitated by the LAPS there was only one survivor. He was discharged from hospital with severe neurological injury and died three months later.

Conclusions-The outcome for established prehospital paediatric cardiac arrest, in a well defined emergency medical services system, is very poor at present. It does not seem to be affected by the institution of paediatric life support teaching programmes for hospital staff alone. The timing in instituting advanced life support measures remains the most critical factor affecting outcome in these patients.

( Accid Emerg Med 1997;14:357-362)
\end{abstract}

Keywords: paediatric cardiac arrest; advanced life support skills; emergency medical services

Leicester LE1 $5 W W$

UK

T B Hassan

Correspondence to: Dr Tajek B Hassan,

Honorary Senior Registrar in A\&E Medicine.

Accepted for publication 13 June 1997

The last four years have seen a rapid expansion in the United Kingdom of advanced life support programmes targeted at the critically ill or injured child. ${ }^{1-3}$ Personnel attending such courses gain knowledge and psychomotor and attitudinal skills that they can apply to acute paediatric care. The courses focus on the need to recognise and treat impending cardiopulmonary compromise and to prevent arrest. A significant amount of time is also given to management of paediatric cardiac arrest which, although infrequent, is generally regarded as having a poor outcome. However, there are few data from the United Kingdom on whether skills acquired from such programmes are effectively used in acute resuscitation and can influence outcome. Buss et al ${ }^{4}$ identified marked deficiencies in the knowledge of personnel who are likely to be team leaders in paediatric cardiac arrest, even among those who had attended a recognised APLS (advanced paediatric life support) course. Survival rates from previously reported studies of paediatric cardiac arrest vary from $0 \%$ to $47 \%,{ }^{5-9}$ the variations being related either to combined reporting of prehospital and in-hospital paediatric cardiac arrests or to variations in defining the end points in successful resuscitation and survival. In studies involving prehospital paediatric cardiac arrests only, survival ranges from $0 \%$ to $9 \%$, with the exception of Hickey et al, ${ }^{10}$ who reported $27 \%$ from Columbus, Ohio, USA. It is notable, however, that 14 of the 15 survivors in this study had a return of spontaneous circulation before arrival in the emergency department, and inclusion criteria included patients who had received resuscitation from persons other than emergency medical services (EMS) personnel. This study is the first to review recorded cases of paediatric cardiac arrest admitted to the accident and emergency (A\&E) department of a single UK centre over a four year period since the progressive introduction of paediatric advanced life support training programmes for hospital staff. The aim was to define the incidence, aetiology, prehospital/in-hospital interventions, and final outcome in such cases, using the paediatric Utstein template ${ }^{11}$ to provide a uniform system of reporting, and hence to identify those factors or skills which are consistent with a successful outcome. Importantly, it also aimed to act as a focus for developing a strategy to train paediatric advanced life support skills to prehospital personnel in Leicestershire.

\section{Methods}

The Leicester Royal Infirmary is a 1100 bed hospital, of which 127 are paediatric. It has five children's intensive care and 26 neonatal intensive care beds. The A\&E department provides the only 24 hour facility for emergency patients in Leicester and sees approximately 
110000 new patients per year, of whom some 30000 are children. The hospital serves the city of Leicester with a population of 300000 , and the county with an additional 600000 , covering an area of 830 square miles. However, patients at the edges of the county are usually taken to a nearby hospital outside the county. The distribution of the paediatric population in 1996 was as follows (upper age range being up to that birthdate): $0-1$ years, $9800 ; 1-4$ years, 52000 ; 5-14 years, $119500 ; 15-16$ years, 12900 . Cardiac arrest was defined by the paediatric Utstein style ${ }^{10}$ as cessation of cardiac mechanical activity, determined by the inability to palpate a central pulse, unresponsiveness, and apnoea. The A\&E notes of all children (aged up to their 16th birthday) with this diagnosis in the prehospital phase or on arrival in the $A \& E$ department for a four year period from 1 January 1992 and 31 December 1995 were reviewed. Patients with obvious irreversible signs of death (rigor mortis or massive head injury) were separately categorised.

The patients were identified by hand searching the resuscitation room log books as well as the departmental computer system and the intensive therapy unit (ITU) database. Notes were reviewed for basic demographic data, relevant time intervals, prehospital and $A \& E$ departmental advanced life support interventions, length of stay on ITU, final diagnosis, and outcome. Data were reformatted in the paediatric Utstein style.

During the study period, the resuscitation team for patients suffering a paediatric cardiac arrest normally consisted, on a 24 hour basis, of a middle grade $\mathrm{A} \& \mathrm{E}$ physician, a middle grade paediatrician, an ITU registrar, a junior doctor from the $A \& E$ department, an operating department assistant (ODA), and at least three trained $A \& E$ nursing staff. By the end of the first year, all of the middle grade $A \& E$ physicians had attended a recognised paediatric life support teaching programme. During this period the Leicestershire Ambulance and Paramedic Service (LAPS) increased its complement of fully trained paramedic staff from 45 in 1992 to 80 by the end of 1995 . Although fully trained to perform advanced life support manoeuvres on adults, paramedics during this time were not trained or officially allowed to perform intubation and intravenous cannulation on children. The remainder of the prehospital personnel were made up of emergency medical technicians (EMTs) who had been trained to perform paediatric basic life support only. Clinical information was collected from a combination of the prehospital incident forms,

Table 1 Prehospital time intervals for relevant groups of patients with cardiac arrest

\begin{tabular}{llll}
\hline & $\begin{array}{c}\text { Call-response } \\
\text { time interval }\end{array}$ & $\begin{array}{l}\text { At scene } \\
\text { time interval }\end{array}$ & $\begin{array}{c}\text { Transfer time to } \\
\text { A\&E department }\end{array}$ \\
\hline $\begin{array}{l}\text { Patient died at scene or certified in A\&E } \\
(\mathrm{n}=32)\end{array}$ & $7 \mathrm{~min}(3-16)$ & $7 \mathrm{~min}(2-22)$ & $8 \mathrm{~min}(3-25)$ \\
$\begin{array}{c}\text { Patient survived to discharge from A\&E to } \\
\text { ITU (n=9) }\end{array}$ & $8 \mathrm{~min}(4-12)$ & $10 \mathrm{~min}(2-22)$ & $10 \mathrm{~min}(5-30)$ \\
$\begin{array}{c}\text { Patient survived to discharge from hospital } \\
(\mathrm{n}=3)\end{array}$ & $7 \mathrm{~min}(3-10)$ & $4 \mathrm{~min}(2-8)$ & $7 \mathrm{~min}(6-9)$ \\
\hline
\end{tabular}

Prehospital records unavailable in five patients.

$A \& E$, accident and emergency department; ITU, intensive therapy unit.
$\mathrm{A} \& \mathrm{E}$ notes, and where relevant the ITU and in-hospital notes.

\section{Results}

During the four year period, 51 children (aged less than 16 years) were brought to the $A \& E$ department in cardiac arrest. In eight cases there were irreversible signs of death and no further resuscitation efforts were made after arrival in the A\&E department. LAPS, whose protocols do not allow for certification of death, continued with basic life support in these patients. There were no secondary transfers from other hospitals.

The median age of the entire cohort was 3.2 years (range two days to 15 years). Seventeen patients $(34 \%)$ were under six months of age, seven (14\%) were aged six to 12 months, eight $(16 \%)$ were aged one to four years, six $(11 \%)$ were aged five to nine years, $10(19 \%)$ were aged 10 to 14 years, and three $(6 \%)$ were aged 15-16 years, with male to female ratio of 1.25:1.

The cardiac arrest was witnessed in 10 of 21 cases $(49 \%)$ where it had been recorded. All the ultimate survivors had a witnessed cardiac arrest. Basic life support by family (bystander cardiopulmonary resuscitation (CPR)) until the arrival of LAPS was provided in eight of 28 patients $(29 \%)$ where this was recorded. None of the eight survived. The relevant prehospital time intervals are recorded in table 1 for all patients except seven. In two of the latter, the patients were rushed to the $A \& E$ department by the parents, bypassing the emergency services. Both were in cardiac arrest on arrival. In the other five, the relevant prehospital documentation had been lost. The three patients brought to hospital by ambulance who ultimately survived had the shortest prehospital time, although in two of the three the arrest occurred on arrival at $\mathrm{A} \& \mathrm{E}$.

The most frequently identified first rhythm in the 43 patients in whom continued resuscitation was thought appropriate was asystole $(85 \% ; 37$ of 43$)$. Five of the 43 patients presented with pulseless electrical activity; four of the ultimate survivors came from this group. Only one patient presented with a first recorded rhythm of ventricular fibrillation in the A\&E department. This was a six year old boy who collapsed following an acute asthmatic attack. He died in the resuscitation room following 52 minutes of resuscitation. The mean length of resuscitation for the 23 patients in whom it was recorded was 29 minutes ( 5 to 52 minutes).

Table 2 outlines the advanced life support skills and drugs used in the prehospital phase and in the A\&E department by the resuscitation team. In only three cases was an advanced life support skill (intubation) used by LAPS. In one of these, oesophageal intubation was inadvertently performed and was subsequently corrected in the $A \& E$ department. In $A \& E$, endotracheal intubation was performed in most cases, apart from two where a bag-valvemask technique was thought to be appropriate. Vascular access was achieved most often using the intraosseous route. The first resuscitation 
Table 2 Advanced life support skills and drug treatment used in paediatric cardiac arrest

\begin{tabular}{llc}
\hline & Prehospital & $\begin{array}{l}\text { AGE } \\
\text { department }\end{array}$ \\
\hline Airways interventions & & \\
Intubation & 38 \\
Bag-valve-mask technique & Not stated & 2 \\
Vascular access & - & 15 \\
Intravenous & - & 26 \\
Intraosseous & - & 3 \\
Central/femoral line & - & 40 \\
Drug treatment & - & 18 \\
Adrenaline & - & 14 \\
Atropine & - & 7 \\
Sodium bicarbonate & - & 4 \\
Calcium chloride & - & 1 \\
20\% Dextrose & - & 1 \\
IV salbutamol & & \\
IV aminophylline & & 9 \\
Fluids & & 7 \\
$\quad$ Human albumin & & \\
Synthetic colloid & & \\
Defibrillation & & \\
\hline
\end{tabular}

A\&E, accident and emergency; IV, intravenous. drug used (apart from oxygen) was adrenaline in 40 of the 43 patients. Adrenaline was not required in three of the ultimate survivors, who were managed with airway measures and oxygen treatment alone. Interestingly, sodium bicarbonate was used in 14 resuscitation attempts, although its use has been discouraged in resuscitation guidelines. Calcium chloride was used in seven patients, though it is not recommended as a resuscitation drug, ${ }^{12}$ apart from in specific circumstances. Defibrillation was used at some stage in the resuscitation phase in seven patients.

Figure 1 shows the outcome of the 43 patients. Although 15 of them (37\%) survived to discharge from $A \& E$, only five (11.5\%) survived to discharge from hospital. However, of the 37 patients who had had a cardiac arrest in the prehospital setting and been brought to $A \& E$ by LAPS there was only one survivor

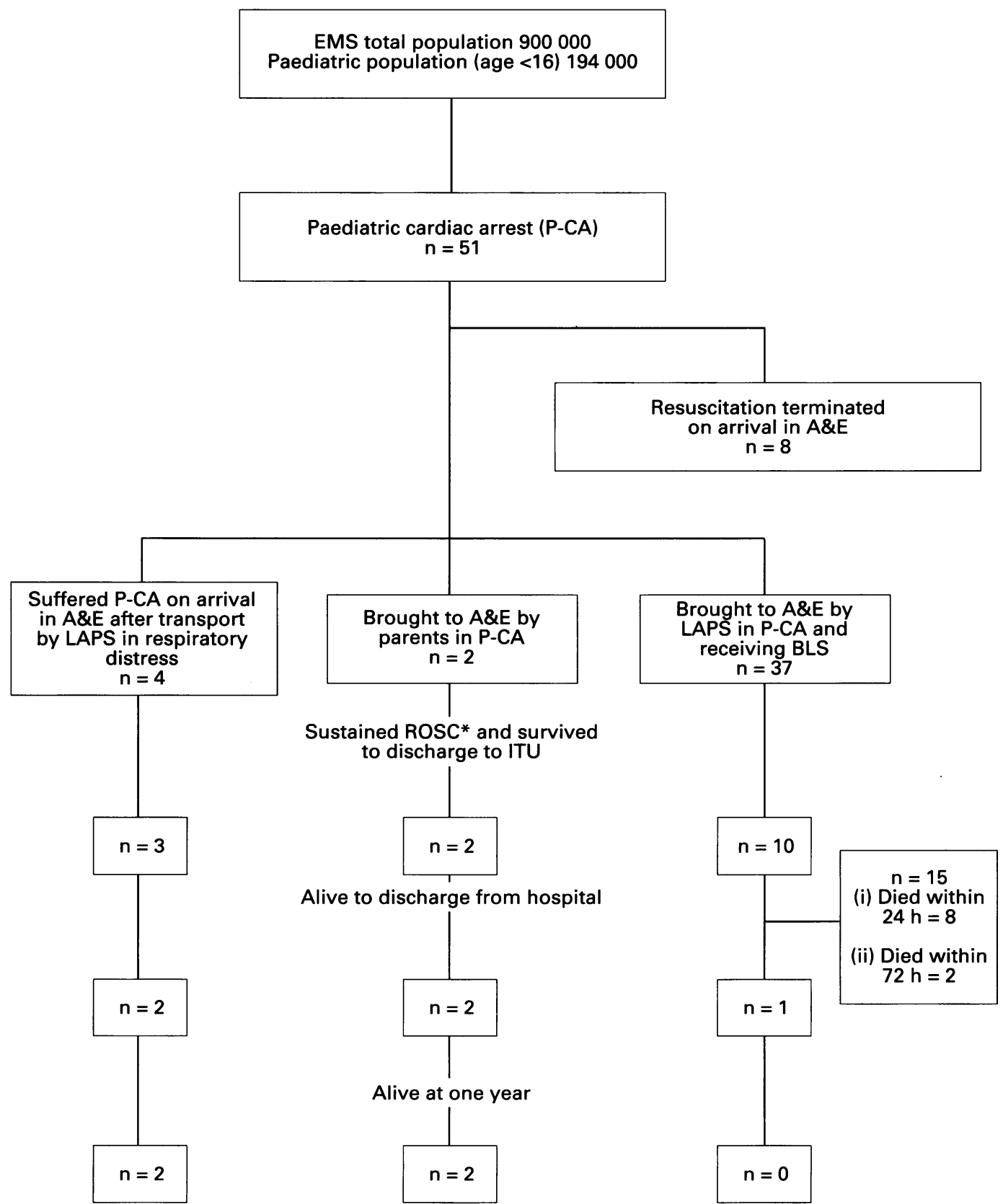

Figure 1 Overview of paediatric cardiac arrest patients admitted to the AEE department. ${ }^{\star} R O S C$, return of spontaneous circulation. 
Table 3 Aetiology of acute causes of paediatric cardiac arrest

\begin{tabular}{ll}
\hline & No of patients \\
\hline SIDS & $13(6)^{\star}$ \\
Trauma & $6(2)^{\star}$ \\
Drowning & 1 \\
Hanging & 2 \\
Respiratory & \\
$\quad$ Foreign body & 1 \\
Pneumonia & 2 \\
Bronchiolitis & 3 \\
Asthma & 3 \\
Cystic fibrosis & 1 \\
Cardiovascular & \\
$\quad$ Congenital heart disease & 4 \\
Cardiomyopathy & 1 \\
Central nervous system & \\
$\quad$ Infection & 2 \\
Haemorrhage & 2 \\
Leucodystrophy & 1 \\
Muscular dystrophy & 1 \\
Drug ingestion & 1 \\
Anaphylaxis & 1 \\
Burns & 1 \\
Neoplasms & 2 \\
Metabolic defect & 1 \\
CHARGE syndrome & 1 \\
Unknown & 1 \\
^
\end{tabular}

* Signifies patients who were certified dead on arrival to A\&E. SIDS, sudden infant death syndrome.

(2.3\%). Of the patients who died on the ITU, eight did so within 24 hours and two others within three days of admission. The sudden infant death syndrome (SIDS) was the single most common cause of death in the 51 cardiac arrest patients (table 3). Diagnoses were based on the coroner's necropsy findings or known pathological causes. The marked variety of acute causes for cardiac arrest in a paediatric population is particularly notable.

The characteristics of the five survivors and the advanced life support skills employed are shown in table 4 . Four of the five had suffered a cardiac arrest in close proximity to or on arrival in $A \& E$. This short critical interval was undoubtedly the major factor in their survival. Three of the five responded to airway interventions and oxygen treatment alone. The patient with bronchiolitis (case 2 ) required prolonged ITU and hospital care, including extracorporeal membrane oxygenation (ECMO) treatment for a week. Case 5 was a three month old baby who was the only survivor of a prehospital cardiac arrest. The cause of his arrest was diagnosed as being a near-miss SIDS event. He was discharged from hospital with severe neurological injury and died three months later.

\section{Discussion}

This descriptive study has identified the incidence and wide spectrum of acute causes for prehospital paediatric cardiac arrest in a well defined EMS system in the United Kingdom. It has confirmed the very poor outcome for children suffering a cardiac arrest in the community who are then transferred to hospital by ambulance (one survivor out of 37, $2.7 \%$ ). In contrast, in those circumstances where patients were brought to the $A \& E$ department by their parents or who arrested on arrival at the hospital the survival rate was very much greater (four out of six patients). This emphasises that the timing of instituting advanced life support measures is the critical factor affecting outcome.

The interventions performed by LAPS shows that the EMS system, like many others in the United Kingdom, is still in the early stages of evolution in terms of paediatric advanced life support skills, and had adopted a "scoop and run" policy in almost all cases during the study period. In contrast, in systems where prehospital paediatric advanced life support skills are well established, survival rates are higher although patients have a greater likelihood of neurological sequelae. Losek et $a l^{12}$ reviewed 114 pulseless, non-breathing, paediatric patients and found nine survivors (8\%). Only three had no neurological sequelae. Seventy five were intubated by the paramedics before arrival in hospital; $58 \%$ of patients less than 18 months old were intubated, compared to $86 \%$ of patients aged between 18 months and 12 years. They concluded that although cardiac arrest was very infrequent in children, endotracheal intubation was often the most crucial step in stabilising the paediatric patient (especially those under 18 months of age) and paramedics should have continuing education targeted at this aspect of resuscitation.

Moygazel et $a l,{ }^{13}$ in the King County EMS system with its high levels of CPR trained citizens, telephone assisted CPR, and aggressive prehospital care, achieved only a $9 \%$ survival rate (15 of 157 patients), eight of whom had severe neurological disability. In this system the highest reported rates of prehospital intubation (96\%), vascular access (92\%), and defibrillation $(93 \%$ of those whose first identified rhythm was ventricular fibrillation) were achieved. Hickey et $a^{10}$ also reported high rates of prehospital intervention and interestingly achieved $27 \%$ survival to discharge; this decreased to $12.5 \%$ when the analysis was adjusted to conform to other studies. This study also provided a cost analysis of the hospital care of such patients and noted that $\$ 566000$ was spent on the 55 children who

Table 4 Characteristics of the survivors from paediatric cardiac arrest

\begin{tabular}{|c|c|c|c|c|c|c|}
\hline Age & Sex & Mode of transport/place of arrest & $\begin{array}{l}\text { Initial } \\
\text { rhythm }\end{array}$ & Aetiology & $\begin{array}{l}\text { Days in } \\
\text { hospital }\end{array}$ & $B L S / A L S$ skills used \\
\hline (1) 18 months & $\mathbf{M}$ & $\begin{array}{l}\text { Tranferred by LAPS. Arrest on arrival } \\
\text { in A\&E }\end{array}$ & PEA & Choked on dummy & 2 & Airway cleared + given oxygen \\
\hline (2) 5 weeks & $\mathrm{F}$ & Brought to $A \& E$ by parents in car & PEA & Bronchiolitis & 21 & Given BLS via bag-valve-mask + oxygen \\
\hline (3) 2 years & $\mathbf{M}$ & $\begin{array}{l}\text { Transferred by LAPS. Arrest on arrival } \\
\text { in A\&E }\end{array}$ & PEA & $\begin{array}{l}\text { Ingestion of amyl } \\
\text { nitrate }\end{array}$ & 3 & Endotracheal intubation, CPR \\
\hline (4) 12 years & $\mathbf{M}$ & Brought to $A \& E$ by parents in car & PEA & Anaphylaxis to "cola" & 4 & Endotracheal intubation, IV access, adrenaline \\
\hline (5) 3 months & $M$ & Transferred by LAPS & Asystole & Near-miss SIDS & 42 & $\begin{array}{l}\text { Endotracheal intubation, intraosseous line, } \\
\text { adrenaline }\end{array}$ \\
\hline
\end{tabular}

A\&E, accident and emergency department; ALS, advanced life support; BLS, basic life support; CPR, cardiopulmonary resuscitation; LAPS, Leicestershire Ambulance and Paramedic Service; PEA, pulseless electrical activity; SIDS, sudden infant death syndrome. 
arrived in the emergency department following unsuccessful resuscitation in the field, with only one ultimate survivor. This child remained in a persistent vegetative state.

At present in the United Kingdom, there is marked variation in the development and use of paediatric life support skills by prehospital personnel. ${ }^{14}$ No data exist on the cost implications and impact on outcome that such programmes might have. Such development should therefore occur in conjunction with a programme of careful audit. Other factors such as criteria based dispatch (and hence potentially shortening response times), telephone assisted CPR, and programmes targeted at increasing basic life support providers in the community could be other factors contributing to additional improvements in the future.

A review of the interventions performed in the A\&E department showed that, although adrenaline was used as the primary resuscitation drug in all cases, there was significant variation in other aspects of drug treatment. Calcium chloride and sodium bicarbonate continue to be used-presumably as a last resort-although they are not recommended. In terms of psychomotor skills, endotracheal intubation was successful in all cases, with no need to resort to needle cricothyroidotomy. The intraosseous route was the commonest form of vascular access $(60 \%)$. It has been proven to a be safe, reproducible, and rapid form of intravascular access both in the prehospital $^{15}$ and the hospital environment. Defibrillation is infrequently used in paediatric resuscitation and in this study only one patient had a presenting rhythm of ventricular fibrillation. It has been suggested that the teaching of defibrillation should be de-emphasised on PALS (paediatric advanced life support) courses as a result of this. ${ }^{16}$ In other studies with rapid response times ${ }^{13}$ ventricular fibrillation has been a more common presenting rhythm. Safe defibrillation is a skill which any person involved in acute resuscitation should be confident in performing. However, in contrast to adult resuscitation, it does not have such a significant effect on eventual outcome in children.

Skills in resuscitating such children can only be properly gained by attending a structured course such as an APLS or PALS. Skill retention is a particularly important issue, especially in paediatric resuscitation. In Leicester, with its particularly busy A\&E department, paediatric cardiac arrest is still very infrequent and a team leader may see only two or three cases per year. A Leicestershire paramedic would deal with such a case even more infrequently, possibly one every seven years. This lack of experience needs to be addressed when developing a training strategy for such personnel. One such programme in the United States significantly increased the knowledge and confidence of emergency care personnel in the management of acutely ill and injured children. ${ }^{17}$ It did not, however, address whether this had any impact on outcome.

Buss et $a l,{ }^{4}$ in a telephone questionnaire, identified marked deficiencies in the knowl- edge of middle grade paediatricians (even among those who had attended an APLS course) in the resuscitation sequence of a child in cardiac arrest. Awareness of such persistent deficiencies among medical staff, especially those who have attained a certain standard (PALS or APLS), may in the future gain the attention of risk managers and lawyers who will expect a certain duty of care. The ultimate responsibility may then lie as much with the consultant responsible for his or her trainee. With this in mind, it is important not only that senior medical staff involved in acute resuscitation attend such courses, but essential that they organise scenarios or moulages to maintain the relevant skills of their trainees.

Adherence to resuscitation guidelines has other advantages as well. It allows the team, often in a highly charged atmosphere, to reach a decision to terminate resuscitation at a much earlier stage, based upon evidence from such studies. Despite this, most childhood resuscitation continues to be prolonged in an effort to do everything possible. In this study, the average resuscitation time was 29 minutes, the longest being 52 minutes. In such situations, the senior nursing team leader may be invaluable in supporting an earlier and appropriate termination of resuscitation.

This study had a number of limitations related to its retrospective design. Some aspects of the data had either not been completed or had been lost, especially the presence or absence of bystander CPR. In addition, the small number of patients precluded any detailed statistical analysis. However, it is the first study in the United Kingdom to analyse in detail the skills used by prehospital and A\&E staff in the management of paediatric cardiac arrest. It has also allowed a baseline to be set both for the Leicester EMS and for the $A \& E$ department in advance of the development of prehospital paediatric advanced life support. Unfortunately the true impact of such resuscitation programmes is difficult to assess when using such crude audit filters as cardiac arrest alone. In the six patients who suffered an arrest just before arrival in the resuscitation room, four survived to discharge from hospital. Although these cases can only provide anecdotal evidence, it does reinforce the importance of early and appropriate advanced life support interventions and the positive effect they can have. In devising such programmes to teach paediatric resuscitation skills to paramedics, doctors, and nurses, it is important to consider not only the time and money for training but more importantly, strategies targeted at the appropriate use and retention of these skills.

In conclusion, this study has confirmed that the outcome for established pre-hospital P-CA in a well defined EMS system in the UK is very poor at present. It does not seem to be affected by the institution of paediatric life support teaching programmes for hospital staff alone. In order to influence outcome, the timing in instituting advance life support measures remains the most critical factor. Further study is required to assess the benefits of developing 
such paediatric skills for prehospital personnel in the United Kingdom.

I would like to thank my colleagues in the $\mathrm{A} \& \mathrm{E}$ department for their valuable comments in the preparation of this manuscript Thanks also to Mrs Jean Thomas for her secretarial support and to Mrs Maria Goldsmith, the departmental audit assistant.

1 American Heart Association. Pediatric advanced life support course, 1989, 1994.

2 Mackway-Jones K, Molyneux EM, Philips B, eds. APLS (UK) course manual. Manchester and Liverpool Universities: ALS courses, 1992.

3 Paediatric Life Support Working Party of the European Resuscitation Council. Guidelines for paediatric life Resuscitation Council. Guidelines

4 Buss PW, Evans RJ, McCarthy G, Scorrer T, Kumar V. Paediatricians' knowledge of cardiac arrest guidelines. Arch diatricians' knowledge of cardiac arrest guidelines. Arch

5 O'Rourke PP. Outcome of children who are apnoeic and pulseless in the emergency room. Crit Care Med 1986;14: 466-8.

6 Lewis JK, Minter MG, Eshelman SJ, Witte MK. Outcome of pediatric resuscitation. Ann Emerg Med 1983;12:297-9.

7 Innes PA, Summers CA, Boyd IM, Molyneux EM. Audit of paediatric cardiopulmonary resuscitation. Arch Dis Child 1993;68:487-91.

8 Ludwig S, Kettrick RG, Parker M. Pediatric cardiopulmonary resuscitation. Clin Pediatr 1984;23:71-5.
9 Wark $\mathrm{H}$, Overton $\mathrm{JH}$. A paediatric cardiac arrest survey. $\mathrm{Br} \mathrm{J}$ Anaesth 1984;56:1271-4

10 Hickey RW, Cohen DM, Strausbaugh S, Dietrich AM Hickey RW, Cohen DM, Strausbaugh S, Dietrich AM.
Pediatric patients requiring CPR in the prehospital setting. Ann Emerg Med 1995;25:495-501.

11 Zaritsky A, Nadkarni V, Hazinski MF, Foltin G, Quan L, Wright $J$, et al. Recommended guidelines for uniform reporting of pediatric advanced life support: the pediatric Utstein Style. Ann Emerg Med 1995; 26:487-503.

12 Losek JD, Hennes H, Glaeser P, Hendley G, Nelson DB. Prehospital care of the pulseless non-breathing pediatric patient. Am J Emerg Med 1987;5:370-4.

13 Moygazel C, Quan L, Graves JR, Tiedeman D, Fahrenbruch Moygazel C, Quan L, Graves JR, Tiedeman D, Fahrenbruch children and adolescents: causes and outcomes. Ann Emerg Med 1995;25:484-91.

14 Simpson HK, Smith GB. Survey of paramedic skills in the United Kingdom and Channel Islands. BMJ 1996;313 1052-3.

15 Seigler RS, Techlenbury FE, Shealy R. Pre-hospital intraosseous infusion by emergency medical personnel: a prospective study. Pediatrics $1989 ; 84: 173$.

16 Schoenfeld PS, Baker MD. Management of cardiopulmonary and trauma resuscitation in the paediatric emergency department. Pediatrics 1993;91:726-9.

17 Smith GA, Thompson JD, Shields BJ, Manley LK, Haley KJ. Evaluation of a model for improving emergency and medical trauma services for children in rural areas. Ann Emerg Med 1997;29:504-10.

The fifth meeting of the sixth series will be held on craniofacial trauma/ facial palsy at Keeble College, Oxford, on 3-4 April 1998. The course is aimed at consultants and trainees in plastic surgery but members of the British Association for Accident and Emergency Medicine are invited to attend. The fee for the meeting will be in the region of $£ 350$, inclusive of one night's accommodation and all meals.

Further details and application form from: The British Association of Plastic Surgeons, The Royal College of Surgeons of England, 35-43 Lincoln's Inn Fields, London WC2A 3PN; tel 0171 831 5161/2; fax 01718314041. 